\title{
XLII. The absorption of water in hot glass. Second paper
}

\section{Carl Barus}

To cite this article: Carl Barus (1899) XLII. The absorption of water in hot glass. Second paper, Philosophical Magazine Series 5, 47:288, 461-479, DOI: 10.1080/14786449908621285

To link to this article: http://dx.doi.org/10.1080/14786449908621285

曲 Published online: 08 May 2009.

Submit your article to this journal ๘

Џ Article views: 2

Q View related articles $\sqsubset$ 
9. Summing up the results obtained we see that:-

(1) It is possible by the observation of Michelson's interference-fringes to separate a double point-source, or detect breadth and ellipticity in a slightly extended source.

(2) But the distance between the two points, or the dimensions of the extended source, must lie within certain limits depending on the length and breadth of the slits $*$.

(3) The dimensions of the slits also considerably affect the general theory, the formulæ obtained not being identical with Michelson's. The law of appearance and disappearance of the fringes depends very largely on the distance between the points or the dimensions of the extended sonrce.

XLII. The Absorption of Water in Hot Glass. Second Paper. By Carl Barus $\dagger$.

1. ATER finishing my account $\ddagger$ of the action of hot A water on glass, observed in fine-bore capillary tubes, it seemed to me that the experiments made several years ago (1891) left questions of considerable interest outstanding. I refer in particular to a further examination of the contents of the capillary tubes. Certain evidence was to be obtained as to the occurrence of syrupy glass at $185^{\circ}$, solidifying to a firm glass when cold, the composition remaining unchanged except as to the water absorbed. Again, as it was improbable that volume-contraction would continue at the same rate indefinitely, the conditions of subsidence were to be determined, together with the effect of the elastic and viscous constants of the tube itself on the apparent volume contractions and compressibilities observed. Questions relative to the acceleration of the reaction at higher temperatures were to be held in view.

Finally, if the inferences drawn from data for capillary tubes are correct, it should be possible to obtain the fusible glass on a larger scale. Experiments in progress in this direction have proved quite successful, and will be described in a later paper. The present remarks are restricted to the experiences with capillary tubes.

2. The apparatus used was the same as that heretofore

* Since the above was read, a paper has appeared in the Comptes Rendus de l'Académie des Sciences for Nov. 28, 1898, dealing with the modifications in Michelson's formulx when we take into account the breadth of the slits. The author, M. Hamy, follows Michelson in not considering variations of intensity parallel to the slits. This, I think, accounts for his results not quite agreeing with mine.

+ Communicated by the Author.

$\ddagger$ Phil. Mag. (5) xlvii, p. 104, Jan. 1899. 
described $(l . c$.$) , a clear thread of water being enclosed in a$ stout capillary tube between terminal threads of mercury, the upper of which was sealed in place, while the lower transmitted the pressure of a force-pump. The motion of each meniscus was observed in the lapse of time through a clear boiling tube (vapour-bath, $185^{\circ}$ to $210^{\circ}$ ) with the cathetometer.

The progress of the experiments may be described, as a whole, as follows:-During the first stages of heating the clear thread of water expands, inasmuch as the constant temperature in question is being approached. After this an initially rapid contraction of the thread is manifest, which must have begun much before the period of constant temperature was reached, so that the full thread-length for $210^{\circ}$ is never quite attained. During the early and most mirked period* of contraction (and some time before) the tube appears white and opaque, and the observer can only with difficulty follow the rise of the lower mercury meniscus. The top meniscus remains in place. Compressibility is a rapidly increasing quantity. During the later stages $\dagger$ of heating the tube becomes transparent again, the mercury-threads stand out brilliantly, and the whitish opaque matter gradually vanishes in the axis of the tube. Contraction becomes less marked and finally ceases; and with it the accentuated compressibility of the aqueous silicate, now so thickly viscid as to retain cavities, also disappears. During this second stage, threads of mercury invariably break off if there is change of pressure. Nevertheless, measurement by means of these indices is not impossible, and in the telescope the observer notices a slow advance of the viscous mass, moving as a whole continually towards the upper end of the tube and carrying the little mercury globules along like debris in a common current.

To measure compressibility at this stage is to face a dilemma : on increasing pressure from below, there is marked increase in the upward motion of the viscous current. It is difficult to state when this accentuated motion ceases. On removing pressure the mercury does not retreat proportionately, if at all. However, when pressure is reduced too far, the mercury may retreat several centimetres, quite out of the field of view, as a whole, leaving well rounded or ovoid cavities behind. Thus it is impossible to make measurements

* Undissolved glass coagulum.

+ Dissolving coagulum 
for compressibility in triplets, and the data are given below with this reservation. These data accentuate the absence of effective volume elasticity under the conditions stated.

When the viscous thread has appreciably ceased to contract (1-2 hours), and the tube is allowed to cool very carefully, bubbles make their appearance very much resembling those in a Prince Rupert drop, and probably due to a similar cause *. They begin to form in the axis, and are usually connected by a fine channel. They may grow to a diameter of over $\frac{2}{3}$ the width of the bore. The formation of these bubbles on cooling is proof that the aqueous silicate is still liquid at the temperature of the vapour-bath $\left(185^{\circ}-210^{\circ}\right)$, however viscous and incompressible it may have become. The solidifying core of water-glass contracts from the centre outward, and must contract more rapidly than the igneousglass envelope. It is this last stage (contents cleared again to a pellucid jelly) which I failed to fully observe in my earlier experiments, believing that solidification had set in when the mercury-threads broke off.

After the tube has passed the final stage with subsidence of contraction, it invariably breaks throughout its length when cold, in such a way as at first sight to suggest expansion on solidification of the aqueous silicate within. It makes no difference how carefully the cooling is performed. If a thread of fusible metal is allowed to solidify in a capillary tube, the latter breaks sooner or later in the same way. I do not by any means imply that the aqueous silicate does actually expand on solidifying, for there are other and better ways in which the breakage can be explained. The appearance of bubbles, for instance, is evidence of contraction, and the breakage is rather due to an excessively shrinking core.

When the cold tube is cut across, the core of water-glass practically fills the tube, and to all appearances is as hard, clear, and firm as the igneous glass surrounding it. There is a difference of refraction between the two glasses sufficient to make the aqueous core apparent under favourable illumination; but for this and the bubbles, the tube would be undistinguishable from a glass rod.

If, however, the end of the glass tube is slightly heated above a candle-flame or a small bunsen-flame, the core soon begins to melt, to swell up enormously in bulk as the result of the frothing which accompanies the escape of steam. The

* It is to be remembered, however, that whereas the Rupert drop is cooled down from above $1000^{\circ} \mathrm{C}$., the present high temperature is only about $200^{\circ}$. 
result is a light, very white pumice, larging exuding from the capillary canal (as shown in fig. 1), the part remaining within resembling pith. In this way the enlarged bore of the tube may be clearly compared with the parts left free
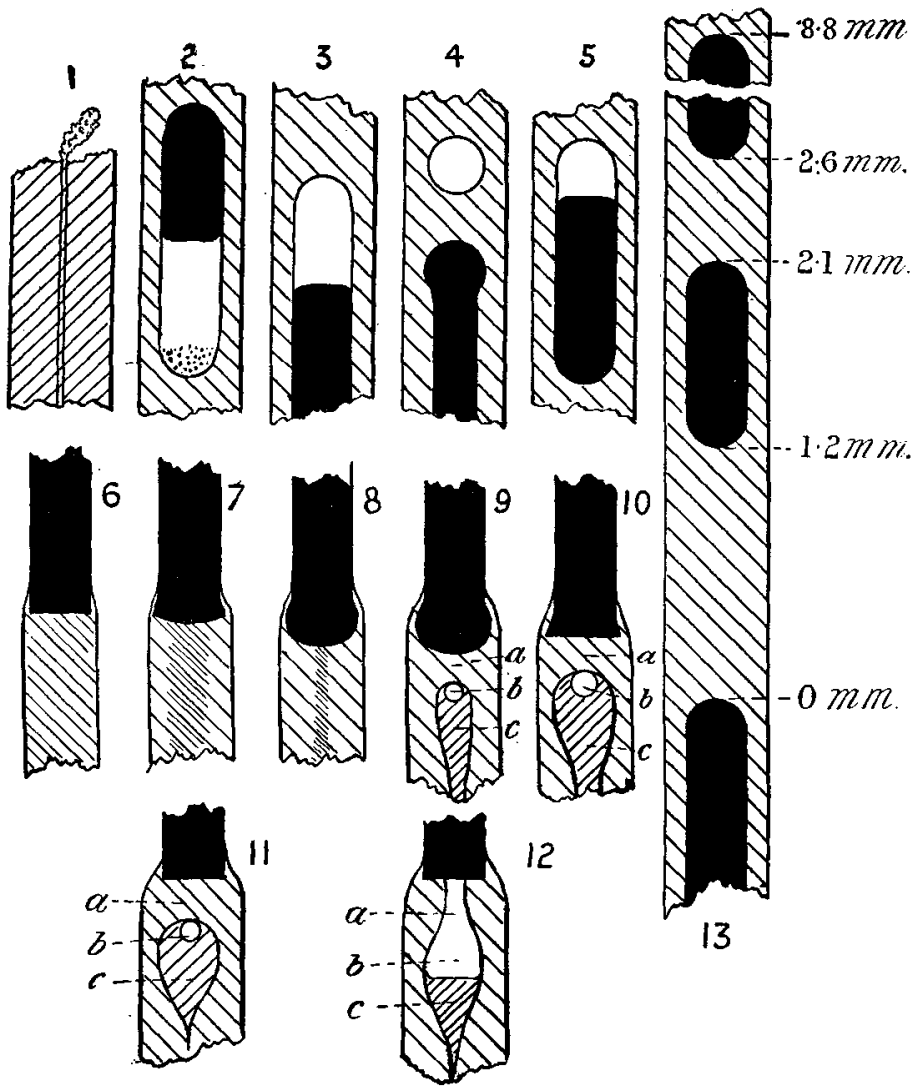

Fig. 1. Capillary tube, with water-glass core heated above.

Figs. 2-13,-Diagrams. The cross-hatched parts denote the core of water-glass (much enlarged), the envelope of igneous glass being ignored. Mercury is shown in black; cavities in white; residual water (?) is diff $r$ rently cross-hatehed. The actual contours were usually more ovoid than these figures.

from water and in contact with mercury only. On further fusion the pumice melts igneously, and, if the glass contains lead, it turns black in the usual way on reduction. 
There is good reason to suppose that the aqueous silicate remains homogeneous from the time of incipient solution to the eventual occurrence of a viscons glassy coagulate, liquid enough at $200^{\circ}$ to admit of the formation of internal bubbles on cooling and contraction, but at the same time viscous enough to keep similar bubbles in shape and position without cooling. A thin thread of water ( 01 to 04 centim. in diam.) is undergoing lateral diffusion into the glass, and concentration difference is virtually confined to the cylindrical surface of contact between igneous glass and water-glass, widening as the action goes on so slowly, that the much more liquid water-glass is free to remain homogeneous. The latter should therefore be identical in composition with the original glass, but for the incorporated water.

In a final experiment (tube No. 7) I put a solution of cobalt nitrate into the tube, rather with the expectation of finding blue water-glass as the result. No such action occurred; instead of it, the water diffused into the glass as usual and the cobaltic nitrate was left as a granular scum in the axis. Chemical decomposition and incorporation of the cobalt did not therefore occur at $200^{\circ}$.

3. Instead of tabulating the large number of observations made (in all seven tubes were employed), it will conduce to clearness to present the work graphically. In so doing, the data for the former tubes may be included, for reference. Time is laid off in intervals of 20 minutes (between vertical lines) along the abscissas, while the ordinates indicate the changes of length of the column of water in intervals of 1 centim. It is not convenient to specify the full length of the thread in the chart; but a datum for the length of the cold thread at about $20^{\circ} \mathrm{C}$. will be given both in the latter and in the tables containing original and final bore, and similar specifications for each capillary tube. These diameters were measured with the cathetometer, the tubes being cut across and looked at endwise. Slight heating increased the sharpness of definition between the original glass and the solid core of water-glass within.

The chart also contains the mean compressibilities $\beta$, for pressure intervals of about $100 \mathrm{~atm}$., no attempt to obtain $\beta$ as a function of pressure being made for the reasons stated in $\$ 2$. Since $\beta=(v / V) / p$, or the decrement of volume per unit of volume per atmosphere, or practically decrement of length per centim. of column per atmosphere, the abscissas as above are successive time-intervals of 10 minutes each, while the scale of ordinates is a change of $\beta$ of $\cdot 000100$. Several 
$\beta$-values are usually attached to the compressibility-curves for orientation.

Calling the two capillary tubes formerly used (preceding paper, 1. c.) Nos. 1 and 2, their dimensional constants before and after corrosion were as follows :-

\begin{tabular}{|l|c|c|c|c|c|}
\hline & $\begin{array}{c}\text { Internal diameter } \\
\text { (centim.). }\end{array}$ & Section. & $\begin{array}{c}\text { Cold thread- } \\
\text { length. }\end{array}$ \\
\hline Original. & Corroded. & Original. & Corroded. & \\
\hline No. $1 \ldots .$. & 043 & .052 & .0015 & .0021 & $18.4 \mathrm{~cm}$. at $28^{\circ}$ \\
No. $2 \ldots . .$. & 042 & .054 & .0014 & .0023 & $14 \cdot 0 \mathrm{~cm}$. at $24^{\circ}$ \\
\hline
\end{tabular}

In these cases the temperature of the vapour-bath was but $185^{\circ}$, and the corrosion did not ontrun the opaque stage. Seen under the microscope, the solid water-glass nearly filled the bore, being an opalescent warty accretion. The chart (p. 470) contains the results for decrement of length of thread and of compressibility so far as observed, after constant temperature had set in. In all these experiments $\beta$ is thoroughly determined * from at least four measurements between 20 and $400 \mathrm{~atm}$. , the initial lengths of thread returning on removal of pressure.

In case of No. 1, time was not observed until after nearly an hour's boiling. The short curves thus refer to the end of the experiments. The general conclusions are stated in the preceding paper.

4. The first of the new tubes to be heated was No. 3, with the following constants :-

Temperature of Vapour-bath, $185^{\circ}$.

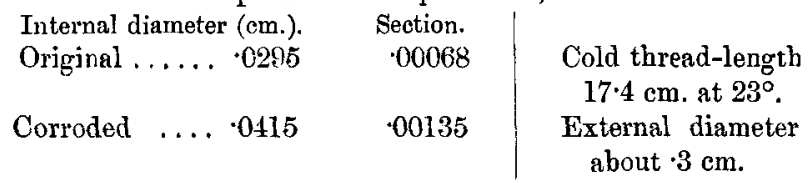

The observations with this tube were not satisfactory; possibly the temperature of the vapour-bath was insufficiently constant; possibly the clear stage of reaction is not reached at $185^{\circ}$ (cf. $\left.\S 12\right)$. The tube turned opaque and so remained. The fouled meniscus was frequently lost, or conld not be

* Cf. Am. Journ, Sci. xli. p. 110 (1891). 
recognized with certainty. No observations were possible until after 30 minutes' boiling.

In the absence of systematic data, however, certain incidental results of interest were obtained with this tube, by observing at high and low temperatures alternately. Thus, after about an hour's boiling, $\beta$ fell off from $120 / 10^{6}$ at $185^{\circ}$ to about $40 / 10^{6}$ at ordinary temperatures. After about $2 \frac{1}{2}$ hours' boiling, $\beta$ fell off from about $230 / 10^{6}$ at $185^{\circ}$ to $90 / 10^{6}$ at ordinary temperatures. After about four hours' boiling the hot compressibilities reached $400 / 10^{6}$; but the tube broke before the corresponding cold compressibilities were measured.

Opportunity was also afforded for roughly measuring the coefficients of expansion of water-glass. After two and a half hours' boiling the mean coefficient per degree was about 002 , between $25^{\circ}$ and $185^{\circ} \mathrm{C}$. The corresponding mean coefficient for pure water, according to Mendeléef ${ }^{*}$, is 0008 to $\cdot 0009$.

Thus it appears that even the relative contraction of waterglass is over twice as large as the normal value for water under like conditions. After four hours' boiling another measurement of the coefficient of expansion of water-glass gave nearly the same result as before. This coefficient did not, therefore, keep pace with the increase of $\beta$; but, as only a small part of the thermal contraction on cooling lies in the region of high temperature to which $\beta$ refers, the two coefficients should not keep pace.

Finally, a comparison between $\beta$ and volume-contraction in the lapse of time showed a change of $\beta$ of about $18 / 10^{6}$ for each per cent. of volume-contraction relative to the cold volume at $20^{\circ} \mathrm{C}$. This mean rate is more rapid than the rate observed for tubes 1 and 2 , or the following tubes.

5. The next tube examined was No. 4, with the following constants :-

$$
\text { Temperature of Vapour-bath, } 210^{\circ} \text {. }
$$

\begin{tabular}{|c|c|c|}
\hline Internal diameter (cm.) & Section. & \\
\hline Original..... 0240 & .00045 & $\begin{array}{l}\text { Cold thread-length } \\
15.43 \mathrm{~cm} \text {. at } 20^{\circ} \text {. }\end{array}$ \\
\hline Corroded .... $\cdot 0710$ & .00396 & $\begin{array}{l}\text { External diameter, } \\
.55 \mathrm{~cm} \text {. }\end{array}$ \\
\hline
\end{tabular}

A higher temperature of exposure $\left(210^{\circ}\right)$ was here chosen for comparison, in order to bring the corrosive action of the

* Phil. Mrg. (5) xxxiii. p. 108 (1892). 
water on glass to an actual period of subsidence, should this be possible. The aqueous silicate obtained was a clear hard core, plainly demarcated from the igneous glass envelope by difference of refraction, but otherwise not readily distinguishable from it. The bubbles contained no water. They were probably partial vacua with traces of steam. A fine axial canal, less than ${ }_{10}^{1}$ millim. in dinmeter, ran apparently through the water-glass core, threading the bubbles. The column of water shortened at $210^{\circ}$ to its original length in the cold tube, after about 20 minutes of exposure. The transparent stage was reacherl in this tube earlier than usual, even at $210^{\circ}$. Indeed, the solvent action was energetic throughout, as is evidenced by the rapid volume-contraction. The chart gives the successive values of volume and compressibility $(\beta)$ in the lapse of time. The quantity $\beta$ is an estimate, since observations in triplets could not be obtained, increase of pressure corresponding to an increment in the continued volume-contraction.

Boiling began at $2^{\mathrm{h}} 40^{\mathrm{m}}$, and constant temperature * was reacbed at $2^{\mathrm{h}} 55^{\mathrm{m}}$. Pronounced volume-contraction had set in before this. The lower meniscus was lost as such before $2^{\mathrm{h}} 60^{\mathrm{m}}$. On increasing pressure the column ascended in form of a succession of ovoid drops with constrictions between them, the mercury diameters being smaller than the bore. Removal of pressure frequently separated these drops altogether, the viscous glass flowing in between them. Indeed the mercury often retreated in such a way as to leave the cavity half empty. In figure 2 (p. 464) I have drawn an interesting case observed at $3^{\mathrm{h}} 3^{\mathrm{m}}$. The mercury fills only the top half of the cavity left on reducing pressure. Very soon after the metal was seen falling to the bottom in a rain of very small drops. Since the diameter of the cavity did not exceed $\frac{1}{3}$ millim., the extreme fineness of these drops is remarkable even at $210^{\circ}$. On slightly increasing pressure again everything was seen to move upwards in a regular eurrent, meniscus (below), detached mercury drops and threads, and the cavities. At $3^{\mathrm{h}} 20^{\mathrm{m}}$, the mercury still showed increased advance on raising the pressure to about $100 \mathrm{~atm}$.; but on withdrawing pressure the mercury did not retreat. I measured the large compressibility $\beta=\cdot 000440$ for these conditions. Even at $3^{\mathrm{h}} 30^{\mathrm{m}}$ cavities half filled with mercury were much in evidence. At $3^{\mathrm{h}} 50^{\mathrm{m}}$ the column of aqueous silicate was nearly clear and continuous, and the compressibility now measured was found enormously reduced, perhaps less than the normal compres-

\footnotetext{
* See Chart (p. 470), curve No. 4, for time and length increments, \&c.
} 
sibility of water at $210^{\circ}$. After this, the action of water on the glass seems to have ceased, no further contraction occurred even up to $4^{\mathrm{h}} 40^{\mathrm{m}}$, when the tube burst at $100 \mathrm{~atm}$.

The chief result obtained from this tube is therefore the certain evidence of an eventual subsidence of the reaction of the water on the glass under given circumstances. The rapidity of reaction, the occurrence of floating cavities partly full of mercury, partly of steam (?), the gradual reabsorption of this steam (?) by the glass on increasing pressure, are to be noted. During the continued volume-contraction compressibility $\beta$ increased rapidly at first, reaching a maximum, and then fell off rapidly to the probable normal value for water at $210^{\circ}$, with the subsidence of further volume-contraction.

From my recent experiments on the compressibility of coagulated colloids*, I infer that the water-glass has now reached a similar stage. A convex meniscus forced upward by pressure changes to a conoid with apex sharpened upward. Removing pressure restores the convex form. Hence the column now possesses definite rigidity, and its viscosity requires long intervals of time to be put in evidence. Sharp axial lines, .05 millim. in diameter, true canals, together with bubbles strung on them like beads, were left after cooling. The axial lines are present at $210^{\circ}$, and then appear as the last vestige of the opaque or granular stage which precedes the clear stage. If there is really something granular about the former, and if the contraction of volume is a cementation of these granules into a homogeneous clear column of aqueous colloidal silicate, then the large final compressibilities are in a measure accounted for ; but the compressibilities for tubes 1 and 2 are real in so far as all observations were made in triplets, and the fiducial zero was regained after high pressures $(400 \mathrm{~atm}$.). The granular hypothesis is thus quite inadmissible even if the interstices between the granules were supposed to contain non-saturated steam; for pressures increasing to above $400 \mathrm{~atm}$. would soon wipe out the maximum vapour-tensions of $11-12$ atm. at $185^{\circ}$, and less than $20 \mathrm{~atm}$. at $210^{\circ}$.

At the close of the experiment the diameter of the mercury thread seemed to be somewhat over one half that of the core of aqueous silicate. Since the bore increased from $\cdot 24$ to . 71 millim., the mercury thread did not thicken much on moving up.

A comparison of compressibility $\beta$ and volume-reduction

* Am. Journ. (4) vol. vi. p. 285 (1898).

Plil. Mag. S. 5. Vol. 47. No. 288. May 1899. $2 \mathrm{~K}$ 


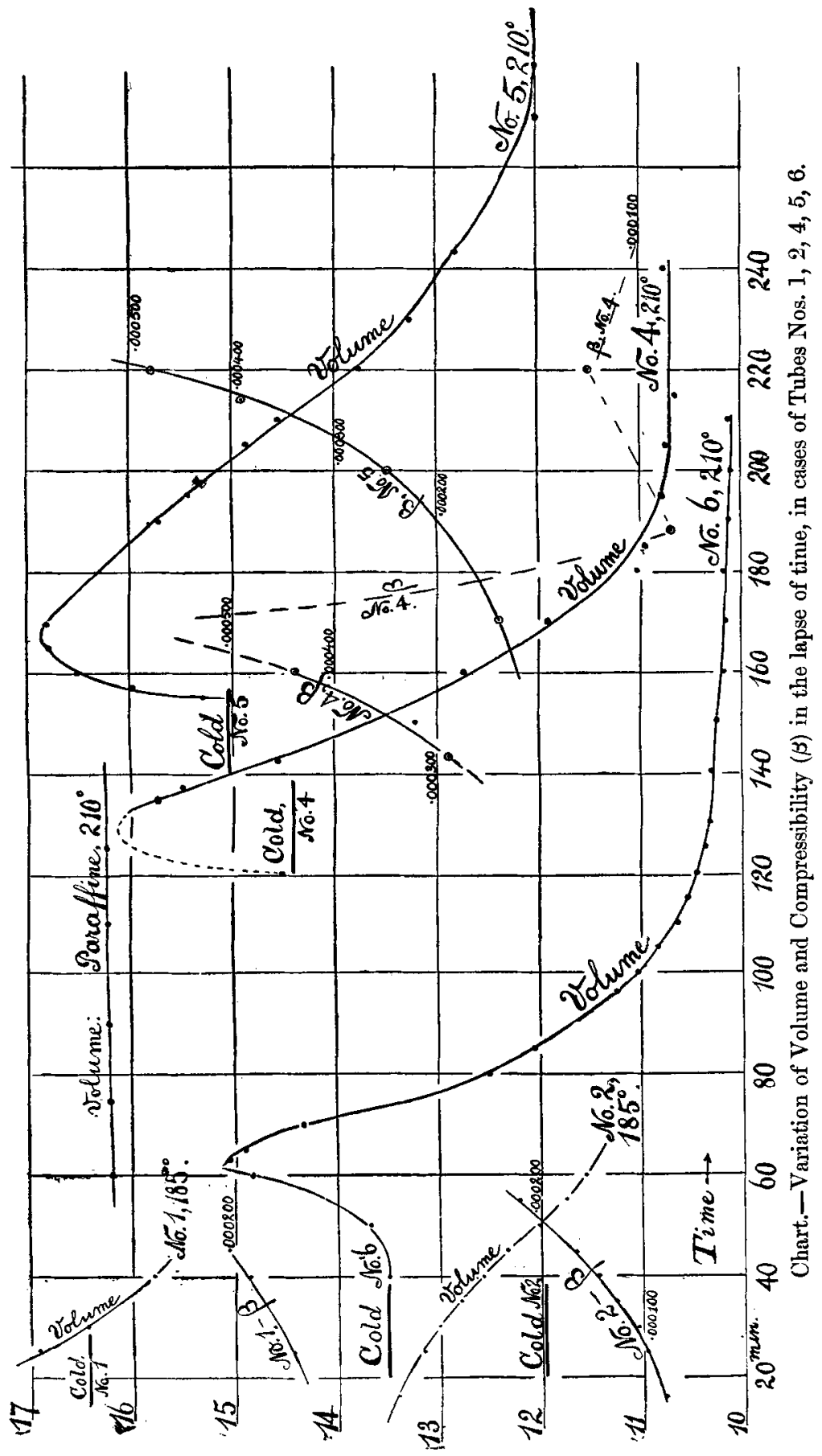


$(v / V)$ for tube No. 4 gave the following interpolated mean values :-

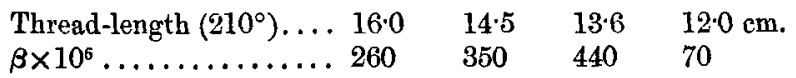

The final datum marks the subsidence of the whole phenomenon, the $\beta$ being nearly the normal datum for water (the usual case of colloids, which retain the compressibility of the solvent), and further volume decrement vanishing. During contraction the mean rate of $\beta$ change is $80 \times 10^{-6}$ per linear $\mathrm{cm}$. of contraction. Since the initial cold length was $15.5 \mathrm{~cm}$., this amounts to about $12 \times 10^{-6}$ for each per cent. of volume decrease relative to the cold volume. This result agrees fairly well with the data for tubes 1 and 2.

6 . The experiments with the next tube, No. 5 , were in the main a corroboration of the results for tube No. 4. The bore was chosen larger.

\begin{tabular}{|c|c|c|}
\hline \multicolumn{3}{|c|}{ Temperature of Vapour-bath, $210^{\circ}$. } \\
\hline $\begin{array}{l}\text { Internal diameter (cm.). } \\
\text { Original } \ldots \ldots .033\end{array}$ & $\begin{array}{l}\text { Section. } \\
\cdot 00085\end{array}$ & $\begin{array}{l}\text { Cold thread-length } \\
14.05 \mathrm{~cm} \text {, at } 20^{\circ}\end{array}$ \\
\hline Corroded ...... 057 & .00260 & $\begin{array}{l}\text { External diameter, } \\
.65 \mathrm{~cm} .\end{array}$ \\
\hline
\end{tabular}

The chart shows the march of volume and of compressibility in the lapse of time. As a whole the reaction is slower than in $\$ 5$; the thread is shortened by contraction at $210^{\circ}$ to its length for the cold tube in about $4 \mathrm{~A}$-minutes, twice as long an interval as before.

Boiling began at $10^{\mathrm{h}} 25^{\mathrm{m}}$, and constant temperature was reached about 15 minutes later. The observations as a whole are the same as in the preceding case. At $11^{\mathrm{h}} 15^{\mathrm{m}}$ the silicate failed to retreat with the advanced mercury column on removing pressure. A peculiar result was observed, as the mercury here ran down several centims., leaving the waterglass full of oval cavities, and afterwards ascended of its own accord to fill them again without manual interference at the force-pump.

I presume that pressure was reduced below the vapourpressure of the water absorbed in glass ; that the temperature of the oil in the force-pump was thermodynamically reduced by expansion of the oil ; that the latter gradually regained its temperature; $\theta$, by conduction, increasing the pressure in the hermetically sealed barrel. Since $d \theta / d p=\alpha v \theta / \mathrm{J}_{c_{\mathbf{P}}}$, a liquid of low specific heat $c_{\mathrm{P}}$, low density $1 / v$, and large thermal expansion $\alpha$, contributes to this result. 
The continuous, very slow contraction current toward the top of the tube was a marked feature. At $12^{\mathrm{h}} 20^{\mathrm{m}}$ pressure increment merely produced marked acceleration in the velocity of this current, removal of pressure leaving the mercury in place. On reducing pressure below a certain value, however, the mercury retreated quite ont of the cavities, as above, to refill them again in the lapse of time. Figure 3 (p. 464) gives a view of a partially emptied cavity of this kind. In figure 4 a globular empty cavity formed during this process is shown, which was made to vanish symmetrically to a point over an advancing mercury meniscus.

The absorption of water in tube 5 virtually subsided after about two hours of boiling. In the finc-bore tube, $\$ 5$, like subsidence set in after but one hour of reaction. Differences of chemical composition are not excluded.

On cooling, bubbles appeared in homogeneous parts of the thread, throughout its length, spontaneously, and expanded often to over half the diameter of the core of water-glass. Moreover, ovoid cavities filled with mercury when hot are found partially empty after cooling, as shown in fig. 5, due to the contraction outward of the walls. The final breakage of this tube was confined to the core, which split across axially, allowing the mercury to enter as a thin sheet without breaking the envelope of igneous glass.

The relations of $\beta$ and $(v / V)$ for this tube may be stated from the following interpolation :-

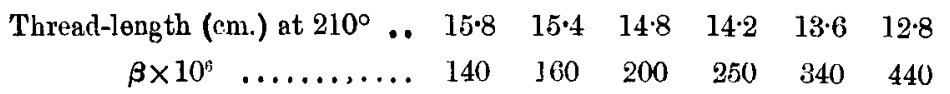

Compressibility increases at an accelerated rate with contraction. Leaving out the final very large values, the mean rate is $93 \times 10^{-6}$ per centim. of contraction. As the cold length of thread is about 14 centim., this is a change of $\beta$ of about $13 \times 10^{-6}$ for each per cent. of volume-contraction referred to the cold volume. The result is thus again of the same order as the data from tubes 1,2 , and 5 .

7. The tube No. 6 was observed specially for volume-contraction, its large bore not being adapted for $\beta$-measurements. The tube when cooled down after corrosion showed a fine, empty, axial canal, about 0063 centim. in diameter, left in the core of aqueous silicate and forming a channel of communication between fourteen large axial bubbles, distributed with fair uniformity along the length of the core. The constants of the tube were (vapour-bath at $210^{\circ}$ ) 


\begin{tabular}{c|c|c}
$\begin{array}{c}\text { Internal diameter }(\mathrm{cm} .) \\
\text { Original............. }\end{array} \cdot 0526$ & $\begin{array}{c}\text { Section. } \\
\cdot 0022\end{array}$ & $\begin{array}{c}\text { Cold thread-length } \\
13 \cdot 5 \mathrm{~cm} . \text { at } 20^{\circ} .\end{array}$ \\
Corroded $\ldots \ldots \ldots \ldots . .1250$ &.$\ldots 119$ & External diameter $68 \mathrm{~cm}$.
\end{tabular}

The march of volume-contraction is given in the chart. Boiling began at $9^{\mathrm{h}} 50^{\mathrm{m}}$ and the temperature was constant $5^{\mathrm{m}}$ or $10^{\mathrm{m}}$ later ; but contraction must have set in long before this. At $10^{\mathrm{h}} 15^{\mathrm{m}}$ the thread appeared indistinct and broken, marking the opaque period. At $10^{\mathrm{b}} 30^{\mathrm{m}}$, though the waterglass was stiil granular, the mercury column, now about twothirds the diameter of the hydrated core, became clearly manifest. At $10^{\mathrm{h}} 55^{\mathrm{m}}$ it stood out brilliantly; the granulations had retreated toward the axis, where they shone on illumination like a white cloud. In fig. 13 a group of mercury threads is given specially measured as to their distance apart. They moved bodily across the crosshairs of the telescope, keeping their position relatively to each other. This seems to be positive proof that the whole internal column is moving upward in consequence of contraction and is followed by the mercury meniscus moving in the direction of constant pressure. In so viscous a mass, a current up in the middle and down at the sides of the bore of about $\frac{3}{4}$ millim. is out of the question.

The deformation of the top of the column of water-glass in this experiment was striking, and is given in successive stages in figs. 6 to 12 , showing its relation to the fixed (upper) mercury meniscus. In fig. 6 the water-glass is opaque and granular; in fig. 7 the granular column is shrinking; in fig. 8 granulations have vanished except in the axis. In fig. 9 the clear water-glass at $a$ shows a steam (?) cavity at $b$, above the residual water (?) at $c$. This deformation may be regarded as an axial opening of the core due to contraction outward. Figures 10 and 11 show successive gradual changes of form of $b, c$ in fig. 9, suggesting an upward march of pressure. Fig. 12 finally shows the gradual deformation of fig. 11, as the result of cooling; but the mercury did not fall down into the channel of fig. 12, which here terminates in the upper meniscus. The expansion of the bubble $b$ is the marked feature. Cooled with great caution, the tube nevertheless broke spontaneously; parts of it after twelve hours, other parts even after months. No liquid water was detected in the cold tube, and the mercury ran freely through the channel in fig. 12. The large rate of reaction is an anomalous feature in view of the large diameter. $C f$. curves $4,5,6$ of chart.

The final tube No. 7, containing a solution of cobaltic 
nitrate, has already been mentioned. The water-glass was not coloured blue, but the salt rejected as a scum in the axis of the tube. Hence the solution appears to be colloidal. In other respects the preceding phenomena were all reproduced, all incisions of the mercury column indicating a current upward in the direction of pressure. Compressibilities were obtained as high as $\beta=400 \times 10^{-6}$.

8 . If the uncertain result for the opaque tube 3 be excepted, the above comparisons of compressibility and volume-contraction as a rule contain data similar to those which corresponded to tubes 1 and 2 , viz.-

$$
\begin{array}{ccccc}
\text { No..... } 1 . & 2 . & 3 . & 4 . & 5 . \\
\delta \beta \frac{\delta \mathrm{L}}{\mathrm{L}_{0}} \ldots 11 \times 10^{-6} & 11 \times 10^{-6} & 18 \times 10^{-6} & 12 \times 10^{-6} & 13 \times 10^{-6},
\end{array}
$$

where $\delta \beta$ is the mean change of compressibility corresponding to the change of length $\delta \mathrm{L}$, and where $\mathrm{L}_{0}$ is the length of the thread when cold (used throughout for want of an available datum at the high temperatures). In view of the difficulty of measuring $\beta$, and of the later stage of reaction for which Nos. 3, 4, 5 apply, the results may be looked upon as of the same order and as a corroboration of Nos. 1 and 2 .

Since the values $\beta$ are apparent compressibilities, the association of values of $\beta$ and volume-contraction may well be looked upon with suspicion: for as the capillary tube during the progress of the reaction increases continually in bore, or in other words is growing less thick-walled, it must at a given pressure yield more and more, and at the same time show continually increasing apparent compressibilities of the contents. A plausible explanation of the correlative variation of $\beta$ and $v / V$ is thus suggested. That it does not hold may be shown as follows:--

To treat the elastic problem first, Tait's equation* for the volume increment of hollow cylinders per unit of volume is available for computation. The true compressibility $\beta_{0}$ thus appears as

$$
\beta_{0}=\beta-\delta \beta=\frac{1}{p}\left(\frac{\delta \mathrm{L}}{\mathrm{L}}-\frac{\delta v}{v}\right)=\beta-\frac{a_{0}{ }^{2}}{a_{1}^{2}-a_{0}^{2}}\left(\frac{1}{k}+\frac{a_{1}^{2}}{a_{0}^{2}} \frac{1}{n}\right),
$$

where $p$ is the internal pressure, $a_{0}$ and $a_{1}$ the internal and external radius of the tubes, $k$ the bulk-modulus, and $n$ the rigidity of the glass. Thus it suffices to find the correction $\delta \beta$ for the original and the corroded tube in order to estimate the value of the elastic discrepancy in question. The follow-

$$
\text { * 'Challenger Reports,' 1882, Appendix, p. } 29 .
$$


ing table contains the results, taking Everett's data (Tables) for $k$ and $n$ :-

\begin{tabular}{|r|c|c|c|c|c|c|}
\hline Tube No................... & 1. & 2. & 3. & 4. & 5. & 6. \\
\hline Original bore $\ldots \ldots . \delta \beta \times 10^{6}=$ & $4 \cdot 2$ & $4 \cdot 2$ & $4 \cdot 2$ & $4 \cdot 2$ & $4 \cdot 2$ & $4 \cdot 2$ \\
Corroded bore $\ldots . . . \delta \beta \times 10^{6}=$ & 4.3 & 4.3 & $4 \cdot 2$ & $4 \cdot 3$ & $4 \cdot 2$ & $4 \cdot 4$ \\
\hline
\end{tabular}

Thus the mean effect of the enlargement of bore, due to internal corrosion, is at ordinary temperatures but $\cdot 0000001$ in the extreme case, or only a few tenths per cent. of the value of $\beta$ for cold water. As an explanation of the changes of $\beta$ obtained, which run as high as 600 per cent., the elastic discrepancy is thus out of the question *.

The effect on the volume-contraction, being $\delta \beta . p$, would be in like degree negligible.

Finally, according to Amagat $\uparrow$ the increase of compressibility of ordinary glass between $0^{\circ}$ and $200^{\circ} \mathrm{C}$. is about 5.9 per cent. Hence even at $200^{\circ}$ the elastic discrepancy will be in almost the same degree negligible as at ordinary temperatures.

In experiments like the above, tubes which initially withstood 400 or 500 atmospheres, after prolonged straining will break even at $100 \mathrm{~atm}$. or less. This result is rather to be ascribed to the fatigue of elasticity or to molecular strains imparted during cooling; for it is not unusual when corrosion is altogether absent.

9. The next point at issue relates to the viscosity of glass at $200^{\circ}$. In a tube subject to viscous deformation the current towards the top may be regarded as the result of viscous stretching due to internal pressure. Increased $\beta$ then represents the initially increased viscons yield accompanying the increased stress, the yield vanishing asymptotically in the lapse of time.

Reasons against this assumption are again of a quantitative kind. When the elastic deformations are not of serious consequence, the viscous changes are apt to be less so. Moreover viscous phenomena would not vanish in one hour as fully as the curves for tubes 4,5 , and $b$ indicate. Finally, in a very large number of experiments in which hydrocarbons

* For experiments in a like direction, see my paper in Am. Journal, (3) xxxix. p. 485 (1890).

$\dagger$ Notices sur les Travaux Sc. de M. E.-H. Amagat, Paris, 1896, p. 36. 
were subjected to much more intense pressures (400 atm.) even at $310^{\circ}$ in capillary tubes, I never noticed volumetric evidence of viscous deformation comparable to the above. Add to this the appearance of the tube; $i$. e., the passage from an opaque corroded interior gradually to a homogenous limpid jelly at the conclusion of the experiment, in parallel with the observed volume changes subsiding in a clear tube, and with the march of compressibility through enormously accentuated values, terminating in the relatively small values for hot water. Finally, after volume-contraction ceases (saturation) there is no further viscous response to any pressure excess whatever.

Viscosity is therefore not available to account for the volumecontraction observed. To make quite sure a special experiment was made with a thread of paraftin, $18 \cdot 19$ centim. long, at $210^{\circ}$ and about $100 \mathrm{~atm}$. After more than an hour's heating (observed $65 \mathrm{~min}$.) the thread had gradually increased in length to 18.23 centim., due no doubt to the gradually rising temperature of the vapour-bath. The data given on the chart (curve marked paraffin) show that there is no relation between the present experiments and the behaviour of water.

10. I therefore regard it as established that the observed volume-contractions are real. The endeavour may now be made to compute limits for the density of the water-glass. I'wo ways suggest themselves: (1) By comparing the initial volume of igneous glass and water with the final volume of water-glass within the same bore (limit of corrosion) ; (2) By making allowance for the advance of the thread of mercury into the column of water-glass. I made these computations for all the tubes; but as the reactions in Nos. 1, 2, 3 are incomplete, Nos. 4, 5, 6 only need be given. The first method in these cases gave $3 \cdot 4,3 \cdot 0,3 \cdot 5$ respectively as the density of solid water-glass. This is obviously a superior limit seeing that the thread does not contract as a whole. The density of the igneous glass is but $2 \cdot 46$. The second method gave me $2 \cdot 40,2 \cdot 25$, and $2 \cdot 35$ respectively as the densities of the water-glass in the three cases. These data present an inferior limit (since the thread of mercury widens in advancing through viscous glass and since the full length of contraction cannot be observed), just as the preceding data are a superior limit. Hence the density of water-glass cannot differ very much from the density of igneous glass $(2 \cdot 46)$. Though the two sets of data differ widely, one may estimate the volumecontraction from their mean value to be about 20 per cent. of the combined volume of igneous glass and water, for complete subsidence of the reaction. 
I may here refer to the apparent expansion on solidification, and the eventual breakage of tubes spontaneously. In a general way, this means an effectively different coefficient of expansion for the igneous glass withont, from that for the water-glass within. Such a result could be brought about, for instance, if latent heat is set free by the water-glass on solidification : for the water-glass is nearly incompressible when solid, and the case would therefore be far different from the solidification of such relatively compressible bodies as paraffin in capillary tubes.

The characteristic formation of bubbles is evidence against expansion on solidification. Indeed I am not sure whether even an excessive contraction of the core may not start an internal crack in the water-glass which thereafter spreads into the igneous glass. Cracked water-glass cores with a sound envelope of igneous glass were a frequent occurrence. Finally, the congealed water-glass in the cold may tend to resume its volume before the volume-contraction was impressed by spontaneous decomposition. The definite decision can bo made only when water-glass has been obtained on a larger scale.

12. Tubes 4, 5, 6 show conclusively that the action of water on glass ceases after the solution has reached a certain degree of concentration ; compared with tubes $1,2,3$, they show that the rate of reaction increases in marked degree with rise of temperature. These observations are in favour of the occurrence of a definite limit of saturation * or even of a definite chemical compound. Reaction, cret.par., ceases with its formation. The marked contraction of bulk as the reaction proceeds may be adduced in favour of the chemical view, since in colloidal solution the volume phenomena are usually secondary.

It is to be noted that, apart from saturation, a gradual subsidence of the rate of reaction would be the result of ordinary colloidal solution, if the concentration gradient at the surface of contact of the water-glass core within and the igneous glass envelope without decreases as more glass enters into solution. The retention of the original composition of the glass with water added, the bodily rejection of colouring material like cobaltic oxide, is further to the point. In how far increased compressibility may be expected in a liquid undergoing colloidal solution I cannot say, even when such solution is accompanied by decreasing volume; but as the phenomenon of solution terminates with a datum very near

* Observing that saturation also occurs in colloids below their melting-point in excess of solvent. 
to the normal compressibilty of water at $200^{\circ}$ (so far as known), I. am led on the whole to favour a colloidal hypothesis. In an extensive study of the solution of vulcanized indiarubber * in a variety of solvents, the fusion temperature of the saturated coagulated colloid under pressure to a clear solution seemed to be nearly independent of the solvent used. Below this temperature there is saturation and swelling, but no solution. One may therefore regard the opaque stage of the reaction of water on glass as the swelling of a coagulated colloid in presence of its solvent, while the melting-point of the coagulated colloidal glass (as evidenced by the second stage of reaction) would lie below $210^{\circ}$, and probably above $150^{\circ} \mathrm{C}$. Another question thus thrusts itself forward : whether the property of swelling is retained by colloids at relatively very low temperatures, seeing that glass at ordinary temperatures does not swell in the presence of water. Finally, the viscosity or stiffness of the fused colloid, and its readiness to coagulate, increases as the amount of solvent per unit of volume decreases.

13. Summarizing the above results, it is best to avoid direct reference to the character of solution, whether colloidal or chemical. An explanation may then be given in terms of the compressibility observed along successive isotherms for the different concentrations of glass solutions at $210^{\circ}$. This at first shows a relatively small value, implying a steep isotherm in a Clapeyron ( $p v)$ diagram. Thereafter compressibility passes through a relatively enormous value (over five times the initial result), implying a nearly horizontal isotherm. 'The reaction ends with even smaller isothermal compressibility than the first observed, implying steeper isotherms than the initial curves. Now, although these isotherms are all at the same absolute temperature, the waterglass is becoming continually more concentrated. Hence the comesponding temperatures of the isotherms in van der Waals' sense are continually decreasing. It follows that the reaction considered as a thermodynamic process is a march through the critical region of certain phases of the water-glass examined.

In the light given by J. W. Gibbs's investigations, one may arrive at clear notions by adopting but two phases of the water-glass for comparison. Many phases may coexist : two are selected in the interest of brevity, and called phase 1 and 2 respectively. During the earlier stages of the reaction (dilute water-glass) phase 1 is stable. At the end of

* Am. Journal, (3) xlii. p. 359 (1891). 
the reaction (concentrated water-glass, subsidence of volumecontraction) phase 2 is stable. Both cases correspond to steep isotherms. Toward the middle region of the reaction (maxima of compressibility) phases 1 and 2 are mutually stable in presence of each otber. Hence the horizontal isotherms corresponding to the critical region are cut through in a march from greater to smaller corresponding temperatures.

That phase 2 is really unstable during the first stage of reaction is shown by the approximate constancy of the values of compressibility throughout intervals of pressure as high as could be applied. For instance at $185^{\circ}$ :

Pressure interval... 20 to 100,100 to 200,200 to 300,300 to $400 \mathrm{~atm}$. $10^{6} \times \beta \ldots \ldots=146 \quad 144 \quad 142 \quad 146$,

and fifteen minutes later,

$$
10^{6} \times \beta \ldots \ldots=188 \quad 176 \quad 201 \quad 189 .
$$

Again, during the intermediate stage water-glass is without volume elasticity; yielding remarkably to increase of pressure, it refuses to expand when pressure is removed. The last stage is again elastic, but relatively incompressible.

The extreme compressibility, $\beta$, of water-glass during the intermediate stage stated deserves special comment. Beginning with igneous glass and water with compressibilities of (say) $\beta=3 \times 10^{-6}$ and $100 \times 10^{-6}$ respectively at $210^{\circ}$, values of $\beta$ are reached which exceed $500 \times 10^{-6}$. One may even compare this result with so volatile a body as ethylic ether ${ }^{*}$ at different temperatures between 100 and $200 \mathrm{~atm}$., as follows :-

$\begin{array}{rcccc}\text { Temp. of ether........... } & 29^{\circ} & 65^{\circ} & 100^{\circ} & 185^{\circ} \\ \beta \times 10^{6} \ldots \ldots \ldots . & 156 & 207 & 305 & 741 .\end{array}$

Yet the water-glass solidifies in the cold to a hard incompressible colourless body, quite resembling igneous glass.

Brown University, Providence, R.I., U.S.A.

* Am. Journal, (3) xxxix. p. 488 (1890). 